Res Dev Disabil Vol. 30(2):386-396 (2009)

ISSN: (print 0891-4222)(online 1873-3379)

doi: 10.1016/j.ridd.2008.07.004

This is a peer reviewed pre-print version of the following article: Effects of risperidone on cognitive-motor performance and motor movements in chronically medicated children, which has been published in final form at: $\mathrm{http}: / /$ www.elsevier.com http://www.elsevier.com/wps/find/journaldescription.cws_home/826/description\#description http://www.sciencedirect.com/science/article/pii/S0891422208000978

(C) 2008 Elsevier Ltd.

\title{
Effects of risperidone on cognitive-motor performance and motor movements in chronically medicated children
}

\author{
Michael G. Aman, Jill A. Hollway, Sarah Leone, Jessica Masty, Ronald \\ Lindsay, Patricia Nash, L. Eugene Arnold
}

\begin{abstract}
This study was designed to explore the placebo-controlled effects of risperidone on cognitive-motor processes, dyskinetic movements, and behavior in children receiving maintenance risperidone therapy. Sixteen children aged 4-14 years with disruptive behavior were randomly assigned to drug order in a crossover study of risperidone and placebo for 2 weeks each. Dependent measures included tests of sustained attention, memory, visual matching, tremor, seat activity, abnormal movements, and parent behavior ratings. Results were compared by repeated measures ANOVA Fourteen boys and 2 girls with disruptive behavior and IQ $\leq 84$ all completed the protocol. Risperidone was superior to placebo on response time $\left(p=0.01, \eta_{\mathrm{P}}{ }^{2}=\right.$ $0.43)$ and seat movement $\left(p<0.05, \eta_{\mathrm{P}}^{2}=0.29\right)$ on a short-term memory task, and on a measure of static tremor $\left(p=0.05, \eta_{\mathrm{P}}{ }^{2}=0.28\right)$. There was not a significant difference between treatment conditions on the Abnormal Involuntary Movement scale. Risperidone was superior to placebo on three subscales of the Nisonger Child Behavior Rating Form [Overly Sensitive $\left(p<0.01, \eta_{\mathrm{P}}{ }^{2}=0.44\right)$, Conduct Problem $\left(p=0.02, \eta_{\mathrm{P}}{ }^{2}=0.36\right)$, Hyperactivity $\left.\left(p=0.03, \eta_{\mathrm{P}}{ }^{2}=0.32\right)\right]$ and on the Hyperactivity/Noncompliance subscale of the Aberrant Behavior Checklist $\left(p=0.01, \eta_{\mathrm{P}}{ }^{2}=0.41\right)$. Significant increases in heart rate $\left(p=0.05, \eta_{\mathrm{P}}{ }^{2}=0.27\right)$ and weight $(p$ $=0.02, \eta_{\mathrm{P}}^{2}=0.36$ ) occurred in the risperidone condition. The findings suggest a beneficial effect of risperidone after several months of treatment on efficiency of responding, activity level, static tremor, and aspects of behavior.
\end{abstract}

\section{Introduction}

Antipsychotics are commonly used for managing certain psychiatric disorders that occur in childhood: schizophrenia, autistic disorder, delusional manic-depressive disorder, and bipolar disorder (Botteron \& Geller, 1998). Antipsychotics have also occasionally been used to manage disruptive behavior disorders [i.e., attention deficit hyperactivity disorder (ADHD), oppositional defiant disorder (ODD), and conduct disorder (CD)] when more conventional treatments, such as psychostimulants and tricyclic antidepressants have failed (Aman, De Smedt, Derivan, Lyons, \& Findling, 2002; Gunther, Herpertz-Dahlman, Jolles, \& Konrad, 2006). The efficacy of risperidone for treating aggression, self-injury, and tantrums has been established in children with autistic disorder (Research Units on Pediatric Psychopharmocology Autism Network, 2002). Despite a helpful role for the antipsychotic medications in many childhood conditions, there is a persistent although poorly substantiated impression that these medicines cause "cognitive blunting" in children. This may be more commonly heard than seen in print, but we believe that it is the cause of considerable resistance to antipsychotic treatment by physicians and nonmedical professionals alike.

At the same time, the limited data regarding cognitive blunting by antipsychotic medicines is largely negative and frequently badly out of date (see Ernst et al., 1999; Aman, 1984; Aman, 
Marks, Turbott, Wilsher, \& Werry, 1991). There are good theoretical reasons to believe that novel antipsychotics may have no effects on cognition or may actually enhance cognitive functioning. The basis for this belief comes from research in schizophrenia, Alzheimer's disease, and in children with disruptive behavior disorder (DBD).

The therapeutic effects of classical antipsychotic medication in treatment of the positive symptoms of schizophrenia are thought to be due to the ability of these drugs selectively to block post-synaptic dopamine D2 receptors and thereby reduce dopaminergic transmission (Stip, Chouinard, \& Boulay, 2005; Honey et al., 1999).

The novel antipsychotic agents have a greater affinity for serotonin $5-\mathrm{HT}_{2}$ receptors than D2 receptors and have been effective in the treatment of both positive and negative symptoms of schizophrenia, including cognitive impairment. Over the last several years, studies have shown significantly improved cognitive performance in schizophrenic patients taking novel antipsychotics in comparison to those taking high-potency classical antipsychotics or no treatment (Bilder et al., 2002; Purdon et al., 2000; Keefe, Silva, Perkins, \& Lieberman, 1999). In one study, investigators found that switching patients from classical to novel antipsychotics improved cognitive functioning (Mori, Nagao, Yamashita, Morinobu, \& Yamawaki, 2004). In other comparative studies novel antipsychotics showed improvements over classical antipsychotics in the areas of attention, verbal working memory, executive function, and in visuomotor tasks (Cuesta, Paealta, \& Zarzuela, 2001; Honey et al., 1999; Green et al., 2000; Gallhofer, Bauer, Lis, Krieger, \& Gruppe, 1996).

However, not all studies have shown an advantage of the novel antipsychotics over the more classical drugs. Geddes, Freemantle, Harrison, and Bebbington (2000), conducted a meta-regression analysis and controlled for medication doses that were higher than the recommended dose of classical antipsychotics used in some trials. They reported only a modest advantage of the atypical antipsychotics in extrapyramidal symptoms over the classical drugs, and the efficacy and tolerability advantage had all but disappeared. Although they did not specifically measure cognitive function, that report suggests that at least some benefits of atypical antipsychotics may be due to higher doses of classical drugs.

Recently, researchers have investigated the therapeutic effects of novel antipsychotics in children with DBD's (e.g., Aman et al., 2002; Snyder et al., 2002). Investigators assessed cognitive function, and they found that there was either no change or beneficial effects (i.e., verbal memory, short-term memory, and attention) with the use of novel antipsychotics (Pandina et al., 2007; Troost et al., 2006; Gunther et al., 2006; MacQueen \& Young, 2003; Borison, 1996; Meltzer, 1995).

Another concern in using antipsychotic medicines with young people is the possibility that they may cause withdrawal or tardive dyskinesia. However, available data on the novel antipsychotics suggests that they may be safer than classical antipsychotics in this respect, especially when taken in small doses. Risperidone is a benzisoxazole derivative with high affinity for the serotonin $5-\mathrm{HT}_{2 \mathrm{~A}}$ and dopamine $\mathrm{D} 2$ receptors and a 5- $\mathrm{HT}_{2 \mathrm{~A}} / \mathrm{D} 2$ affinity ratio of 8:1. Risperidone also binds with moderate to high affinity to the $\alpha_{1}$-and $\alpha_{2}$-adrenoreceptors, $\mathrm{D}_{1}, \mathrm{D}_{3}$, and $\mathrm{D}_{4}$ receptors, and histamine $\mathrm{H}_{1}$ receptors (Toren, Ratner, Laor, \& Weizman, 2004).

The present study was designed to test whether risperidone has an effect on cognitive-motor performance as compared with placebo. Our hypotheses were: (a) that risperidone would have no adverse effects on cognitive-motor performance in children who received maintenance therapy of risperidone for 4-20 months and (b) that children tested during the placebo phase would show no more dyskinetic movements than during risperidone treatment (i.e., there 
would be no unmasking of tardive dyskinesia). A secondary aim was to monitor behavioral changes as these children proceeded through the crossover trial.

\section{Methods and materials}

\subsection{Participants}

The participants were 16 children and adolescents ages 4-14 years inclusive with an IQ $\leq$ 84 who were recruited from two sources. The first group $(n=12)$ comprised children who took part in studies of risperidone efficacy in conduct disorder and oppositional defiant disorder. All of these children were initially selected for the presence of oppositional defiant disorder (ODD) or conduct disorder (CD). They were initially enrolled in an acute, 6-week, placebo-controlled trial (Aman et al., 2002) and then maintained on risperidone for 48 weeks (Findling et al., 2004). The second group comprised 4 children who had been medicated and maintained on risperidone by their physicians and who had a diagnosis of autistic disorder or pervasive developmental disorder not otherwise specified. Inclusion criteria were availability of a reliable informant, and good physical health as determined by history and physical examination. Exclusion criteria were: presence of psychosis, history of neuroleptic malignant syndrome (NMS), history of severe drug allergy or hypersensitivity, a medical disease such as heart disease, hypertension, liver or renal failure, known seizure disorder, or pregnancy. Of the 16 participants, 5 took psychostimulants (see Table 1, sample characteristics). In order to increase sample

\begin{tabular}{lr}
\hline Age, year, mean \pm S.D. & $8.56 \pm 2.6$ \\
Weight (kg), mean \pm S.D. & $52.54 \pm 6.9$ \\
Height (in.), mean \pm S.D. & $78.14 \pm 45.1$ \\
Sex & \\
Male, no. (\%) & $14(87.5)$ \\
Female, no (\%) & $2(12.5)$ \\
Race & \\
White, no. (\%) & $13(81.2)$ \\
Black, no. (\%) & $3(18.8)$ \\
DSM-IV axis I diagnosis & $1(6.2)$ \\
Attention deficit hyperactivity disorder (ADHD) no. (\%) & $2(12.5)$ \\
ADHD plus conduct disorder (CD) no. (\%) & $6(37.5)$ \\
ADHD plus oppositional defiant disorder (ODD) no. (\%) & $1(6.3)$ \\
CD no. (\%) & $3(18.7)$ \\
ODD, no. (\%) & \\
DSM-IV axis II diagnosis & $3(18.7)$ \\
Autism spectrum disorder (ASD) & \\
Intellectual functioning & $10(62.5)$ \\
Average intellectual functioning, no. (\%) & \\
Borderline intellectual disability, no. (\%) &
\end{tabular}




\begin{tabular}{lr} 
Mild intellectual disability, no. (\%) & $4(25.0)$ \\
Moderate intellectual disability, no. (\%) & $1(6.2)$ \\
IQ, mean \pm S.D. & $71.81 \pm 13.4$ \\
Daily dose risperidone, mean \pm S.D. & $1.65 \pm 1.3$ \\
Stable concomitant med at BL; total, no. (\%) & $5(32.0)$ \\
\hline
\end{tabular}

Table 1 Sample characteristics $(N=16)$ size, exclusion criteria were relaxed, and the final subject enrolled received pre-established clonidine and lithium with risperidone. All concomitant medications remained constant throughout the trial.

\subsection{Study design}

This was a double-blind, placebo-controlled, crossover study in which subjects were randomized to drug order. Assignment to drug order was stratified by age (4-9 years and 10-14 years). Each condition lasted 2 weeks. Half of the participants were assigned to a placebo (PBO)risperidone (RIS) sequence and the remainder to a RIS-PBO sequence. Participants received the drug and placebo conditions for 2 weeks each. For the children identified in the community and taking risperidone at the direction of their physicians, participation followed approval by their physicians to take part.

The O.S.U. Institutional Review Board approved the study. After the study was explained to each participant and his or her guardian or legal representative, the participant's guardian or legal representative provided written informed consent.

\section{Procedure}

All participants were assessed with an IQ test [Stanford-Binet Intelligence Scale IV ed. (Thorndike, Hagen, \& Sattler, 1986); Wechsler Intelligence Scale for Children, ${ }^{\text {rd }}$ ed.(Wechsler, 1991); Kaufman Brief Intelligence Test (Kaufman \& Kaufman, 1990)]. Clinical and cognitive assessments were carried out at baseline, week 3 , and week 5 , of each condition. We endeavored to standardize the time of day for the assessments, although a few subjects were not able to arrive at exactly the same time throughout the trial.

\subsection{Dosing and dosing schedule}

Risperidone tablets were supplied by Janssen Pharmaceutica as matching placebo and risperidone tablets in doses of $0.25,0.50$, and $1.00 \mathrm{mg}$. All children were assessed three times: (a) during a screen visit, while taking their usual dose of risperidone; (b) 2 weeks later, while randomly assigned to risperidone or placebo, and (c) 2 weeks later while assigned to the alternative drug condition. Participants receiving the RIS-RIS-PBO sequence were given their usual dose of risperidone at baseline and in weeks 2 and 3. Then in week 4 the risperidone was terminated and placebo was provided. For participants receiving the RIS-PBO-RIS sequence, following week 3, the placebo condition was terminated and risperidone was titrated over the first 6 days of week 4 . The third assessment took place at the end of week 5, when participants assigned to RIS-PBO-RIS sequence were at their full dose for 8 days.

\subsection{Cognitive-motor measures}

Cognitive-motor performance was assessed using three attentional / memory tasks and a measure of fine motor ability designed for children with intellectual disability or pervasive developmental disorder (Aman, 1991). All were controlled by computer, and seat activity was 
measured unobtrusively throughout each of the cognitive tasks.

The first cognitive test was a titrated delayed Matching-to-Sample (MTS) task (Aman, Kern, McGhee, \& Arnold, 1993). This test measures memory for colors. The child was shown a color (red, yellow, or blue) at the center-top of the screen and the child depressed the window where the color appeared (observing response). One second later, the colors red, yellow, and blue were presented at the bottom of the screen. The child's task was to decide which color matched the preceding color and to press the corresponding window. Every time the child made three consecutive correct responses, one second was added to the delay between the stimulus and the test colors. Whenever the child responded incorrectly, $1 \mathrm{~s}$ was subtracted from the delay (down to a minimum of $1 \mathrm{~s}$ ). Dependent measures included mean accuracy, response time, longest delay achieved, and mean delay (s).

The second cognitive test was a Short Term Recognition Memory (STRM) task (Aman, 1991; Sprague \& Sleator, 1977). In this task, the participants were required to look at arrays of 3 or 9 cartoon pictures and to try to remember them. After each array was presented, there was a 4-s delay. Then the child was presented with a single picture and $\mathrm{s} /$ he had to decide whether that was a member of the preceding array (indicated by pressing a "Same", or "Different"' switch). Two dependent measures were recorded, mean accuracy and mean response time.

The third task was a Continuous Performance Task (Aman, 1991). In this task, the participant was told to watch a screen on which pictures of a witch and Snow White were presented over time. Participants were asked to respond by pressing a lever whenever they saw the witch and to refrain from responding when Snow White appeared. Dependent variables included errors of omission (failures to detect the witch), errors of commission (responses to Snow White), and mean response time.

Seat activity was measured while the participants were being tested on the above tasks, using a "wiggle" seat developed by Sprague and Toppe (1966). The platform of the seat had a pivot under its center with microswitches under each of the sides. A slight tilt of the seat activated a microswitch, and activity was recorded cumulatively by the computer.

Finally, the Graduated Holes Task (Kløve, 1963), consisted of a metal plate with several holes drilled in it. The child was told to hold a metal stylus at arm's length in the center of each hole, without touching the sides, for $10 \mathrm{~s}$. This was done for the five largest holes and for each hand separately. The number of contacts and the time of contact between the stylus and the metal plate were electronically recorded.

\subsection{Clinical measures}

Parents rated the children on two standardized checklists. The Nisonger Child Behavior Rating Form (NCBRF) is an informant behavior rating scale developed for assessing children and adolescents with developmental disabilities Aman, Tasse, Rojahn, and Hammer (1995). The NCBRF consists of six problem behavior subscales designated as Conduct Problem, Insecure/Anxious, Hyperactivity, Self-Injury/Stereotypy, Self-Isolated/Ritualistic, and Overly Sensitive. The Aberrant Behavior Checklist (ABC) is another widely used rating scale for assessing behavior problems in subjects with developmental disabilities (Aman, Singh, Stewart, \& Field, 1985a, 1985b; Aman \& Singh, 1994). The ABC subscales are labeled as Irritability, Lethargy/Social Withdrawal, Stereotypic Behavior, Hyperactivity, and Inappropriate Speech.

\subsection{Safety measures}

Safety measures included physician assessments of vital signs, weight, adverse events (AEs), and concomitant medication. In addition to spontaneously reported AEs, potential 
dyskinetic movements were assessed using the Abnormal Involuntary Movement Scale (AIMS). This 12-item scale was developed by the Psychopharmacology Research Branch of NIMH (NIMH, 1985).

\section{Statistical analysis}

Two separate analyses were conducted using the General Linear Models package in SPSS. A mixed ANOVA was conducted to assess whether there were study by drug condition differences in parent ratings and test scores. This was done to determine if the responses of the four children recruited in the community differed from those who were initially in the DBD studies. Next, interval-level data were analyzed as a function of Drug Order (PBO-RIS vs. RIS-PBO) and Drug (PBO vs. RIS). Only data from assessment sessions 2 and 3 were used for the analyses (i.e., the screen was used solely for training purposes). Effect sizes (partial eta squared, $\eta_{\mathrm{P}}{ }^{2}$ ) were provided in addition to $p$-values; they can be informative when power is low due to small sample sizes. In all tests, $p$-values $\leq 0.05$ were used to indicate statistical significance.

\section{Results}

\subsection{Subjects}

The intent-to-treat analysis included all 16 participants However, the analyses were run with and without the data of one boy for the following reasons: (a) the shelf-life for active medicine expired before he took the study medicine (this is the only subject for whom this occurred); (b) his behavior deteriorated precipitously on active medication (we suspected, but could not prove, that drug conditions were inadvertently reversed); (c) this was the only subject to lose weight on putative active medication, again supporting our belief that the conditions may have been reversed. The parent of one child discontinued his medicine in the last treatment phase "because it did not work." This child was tested, as scheduled and his data were retained.

\subsection{Exposure to study medication}

The mean dose of risperidone was $1.65 \mathrm{mg} /$ day $($ S.D. $=1.25)($ dose range $=0.38-5.0$ $\mathrm{mg} /$ per day). The child taking $5.0 \mathrm{mg} /$ day was recruited from the community for the second cohort.

\subsection{Study by drug interactions}

A Mixed ANOVA was conducted to assess whether there were between group differences (cohort 1 vs. cohort 2) in test scores and parent ratings. Study by drug interactions were significant for two variables. Two of the study participants who were randomized to the RIS-RIS-PBO sequence scored positive for dyskinesia on the AIMS while in the placebo phase of the study. Also, there was a significant difference between the two study samples on parent reported stereotypic behavior. Not surprisingly, children in the second cohort (who had PDDs) scored significantly higher on the Stereotypic Behavior subscale of the ABC than children in the first cohort (who had no PDDs). As there were no differences between groups in terms of their drug responses, we combined them for all subsequent analyses.

\subsection{Efficacy measures}

Table 2 shows the outcome means and standard deviations for Drug Order A (RIS-PBO) and Drug Order B (PBO-RIS) on the cognitive-motor measures. Results indicate three significant main effects of drug condition. Compared to placebo, risperidone resulted in faster response times $[F(1,12)=9.20$, 


\begin{tabular}{|c|c|c|c|c|c|c|c|}
\hline \multirow[t]{3}{*}{ Cognitive-motor tasks, $N=15$} & \multicolumn{4}{|c|}{ Cognitive-motor outcomes } & \multicolumn{3}{|c|}{ Drug condition effects } \\
\hline & \multicolumn{2}{|c|}{ Drug order $\mathrm{A}, N=9$} & \multicolumn{2}{|c|}{ Drug order $\mathrm{B}, N=6$} & \multirow[t]{2}{*}{$F$} & \multirow[t]{2}{*}{$p$} & \multirow[t]{2}{*}{$\eta_{P}^{2}$} \\
\hline & $\begin{array}{l}\text { Time } 1-\text { RIS } \\
\text { (mean) }\end{array}$ & $\begin{array}{l}\text { Time 2-PBO } \\
\text { (mean) }\end{array}$ & $\begin{array}{l}\text { Time 2-RIS } \\
\text { (mean) }\end{array}$ & $\begin{array}{l}\text { Time } 1-\mathrm{PBO} \\
\text { (mean) }\end{array}$ & & & \\
\hline \multicolumn{8}{|l|}{ Match-to-Sample task (MTS) } \\
\hline Accuracy & 84.87 & 81.79 & 89.35 & 93.05 & 0.004 & 0.95 & 0.00 \\
\hline Response time & 1.72 & 1.91 & 1.77 & 1.74 & 0.19 & 0.67 & 0.01 \\
\hline Longest delay & 7.22 & 6.89 & 8.00 & 9.33 & 0.25 & 0.62 & 0.02 \\
\hline Mean delay & 3.91 & 3.49 & 4.48 & 4.80 & 0.008 & 0.93 & $\begin{array}{l}0.00 \\
1\end{array}$ \\
\hline Seat movements & 82.67 & 95.11 & 130.50 & 184.00 & 1.78 & 0.21 & 0.12 \\
\hline \multicolumn{8}{|c|}{ Short Term Recognition Memory task (STRM) ${ }^{\dagger}$} \\
\hline Accuracy & 73.44 & 67.71 & 65.97 & 72.22 & 0.003 & 0.96 & 0.00 \\
\hline Response time & 2.66 & 3.19 & 1.85 & 2.16 & 9.20 & 0.01 & 0.43 \\
\hline Seat movements & 104.75 & 169.25 & 170.00 & 312.00 & 4.87 & 0.05 & 0.29 \\
\hline \multicolumn{8}{|c|}{ Continuous Performance Task $(\mathrm{CPT})^{\dagger}$} \\
\hline Omissions & 1.75 & 1.75 & 1.83 & 1.66 & 0.03 & 0.86 & $\begin{array}{l}0.00 \\
3\end{array}$ \\
\hline Commissions & 2.38 & 3.88 & 2.83 & 4.00 & 1.73 & 0.21 & 0.13 \\
\hline Response time (RT) & 0.56 & 0.61 & 0.51 & 0.46 & 0.001 & 0.98 & 0.00 \\
\hline Seat movement & 198.75 & 287.63 & 303.00 & 427.67 & 0.80 & 0.38 & 0.06 \\
\hline \multicolumn{8}{|l|}{ Graduated Holes Task (GHT) } \\
\hline Contacts & 230.63 & 278.00 & 232.83 & 282.17 & 4.95 & 0.05 & 0.29 \\
\hline Error time & 13.24 & 19.46 & 14.32 & 14.64 & 1.96 & 0.19 & 0.14 \\
\hline
\end{tabular}

${ }^{\dagger}$ Sample size $=14$ because 2 subjects did not master the task.

Table 2 Cognitive-motor effects of risperidone (one subject deleted)

\begin{tabular}{|c|c|c|c|c|c|c|c|}
\hline \multirow{4}{*}{$\begin{array}{l}\text { Scales/physiological } \\
\text { outcomes, } N=15\end{array}$} & \multicolumn{4}{|c|}{ Behavioral/physiological outcomes } & \multicolumn{3}{|c|}{ Drug condition effects } \\
\hline & \multicolumn{2}{|c|}{ Treatment condition $1, N=9$} & \multicolumn{2}{|c|}{$\begin{array}{l}\text { Treatment condition } 2, N=I \\
6\end{array}$} & \multirow[t]{3}{*}{$F$} & \multirow[t]{3}{*}{$F$} & \multirow[t]{3}{*}{$\eta_{\mathrm{P}}^{2}$} \\
\hline & Time 1 - RIS & $\begin{array}{l}\text { Time } \\
2-\mathrm{PBO}\end{array}$ & Time 2-RIS & $\begin{array}{l}\text { Time } \\
2-\mathrm{PBO}\end{array}$ & & & \\
\hline & (mean) & (mean) & (mean) & (mean) & & & \\
\hline \multicolumn{8}{|c|}{ Nisonger Child behavior Rating Form (NCBRF) } \\
\hline Conduct Problems & 19.11 & 22.89 & 18.17 & 31.00 & 7.34 & ${ }^{*} 0.02$ & 0.36 \\
\hline Insecurity & 10.67 & 12.22 & 11.67 & 17.17 & 3.77 & 0.07 & 0.23 \\
\hline Hyperactivity & 11.67 & 14.56 & 11.17 & 15.50 & 6.04 & ${ }^{*} 0.03$ & 0.32 \\
\hline
\end{tabular}




\begin{tabular}{|c|c|c|c|c|c|c|c|}
\hline Self-injury & 0.78 & 1.33 & 0.50 & 0.67 & 2.70 & 0.13 & 0.17 \\
\hline Ritualistic & 3.11 & 3.22 & 1.67 & 2.67 & 0.51 & 0.49 & 0.04 \\
\hline Overly sensitive & 5.89 & 8.00 & 4.00 & 7.50 & 10.35 & ${ }^{* *} 0.007$ & 0.44 \\
\hline \multicolumn{8}{|c|}{ Aberrant Behavior Checklist (ABC) } \\
\hline Irritability & 16.44 & 19.33 & 15.33 & 22.83 & 3.18 & 0.07 & 0.23 \\
\hline Lethargy & 5.44 & 4.44 & 4.50 & 6.00 & 0.02 & 0.88 & 0.00 \\
\hline Stereotypic behavior & 1.33 & 2.67 & 0.33 & 1.50 & 1.44 & 0.25 & 0.10 \\
\hline Inappropriate speech & 4.11 & 3.78 & 3.50 & 4.67 & 0.80 & 0.39 & 0.06 \\
\hline Hyperactivity/noncompliance & 19.11 & 26.56 & 21.33 & 32.50 & 8.93 & ${ }^{*} 0.01$ & 0.41 \\
\hline \multicolumn{8}{|l|}{ Physiological outcomes } \\
\hline Systolic BP & 101.56 & 101.22 & 103.00 & 98.67 & 0.93 & 0.35 & 0.07 \\
\hline Diastolic BP & 67.11 & 68.78 & 70.33 & 69.00 & 0.006 & 0.94 & 0.00 \\
\hline Heart rate $(\mathrm{BPM})$ & 95.00 & 80.67 & 93.50 & 88.83 & 4.81 & 0.05 & 0.27 \\
\hline Weight (lbs) & 82.46 & 80.31 & 81.42 & 79.92 & 7.40 & ${ }^{*} 0.02$ & 0.36 \\
\hline
\end{tabular}

$* p \leq 0.05$.

$* * p \leq 0.01$.

Table 3 Effects of risperidone on behavior, vital signs, and weight (one subject deleted)

$\left.p=0.01, \eta_{P}^{2}=0.43\right]$ and fewer seat movements $\left[F(1,12)=4.87, p=0.048, \eta_{P}^{2}=0.29\right]$ on the STRM task and fewer contacts (less tremor) on the Graduated Holes Task $[F(1,12)=4.95, p=$ $\left.0.046, \eta_{P}^{2}=0.29\right]$.

Table 3 shows the outcome means for drug condition on the NCBRF, ABC, and safety outcomes. Results indicate significant main effects of drug on 3 subscales of the NCBRF, with risperidone superior to placebo on Conduct Problem $\left[F(1,13)=7.34, p=0.02, \eta_{P}^{2}=0.36\right]$, Hyperactivity $\left[F(1,13)=6.04, p=0.03, \eta_{P}^{2}=0.32\right]$, and Overly Sensitive $[F(1,13)=10.35, p=$ $\left.0.01, \eta_{P}^{2}=0.44\right]$. Risperidone was also shown to be superior to placebo on the ABC Hyperactivity/Noncompliance subscale $\left[F(1,13)=8.93, p=0.01, \eta_{P}^{2}=0.41\right]$. Heart rate (BPM) increased significantly during the risperidone phase when compared to placebo $[F(1,13)=4.81, p$ $\left.=0.05, \eta_{P}^{2}=0.27\right]$, as did weight gain $(\mathrm{lbs})\left[F(1,13)=7.40, p=0.02, \eta_{P}^{2}=0.36\right]$.

\section{Discussion}

\subsection{Cognitive-motor effects}

The present analysis addressed cognitive functioning because this is a domain that has received very little attention in children thus far. No declines in measures of attention (e.g., CPT) and working memory (e.g., Match-to-Sample Task) occurred with risperidone. On the contrary, there was significant improvement in response time on the Short Term Memory task for the risperidone condition. In addition, there was significant improvement in the number of seat movements on the Short Term Memory task, indicating decreased motility in the risperidone condition. Finally, on the measure of motor steadiness (i.e., Graduated Holes Task), the risperidone condition caused a significant decrease in the number of contacts, suggesting improved motor control compared with placebo. 
Somnolence is a frequent side effect of atypical antipsychotics early in treatment, causing many professionals to wonder if this would result in impaired learning. However, one detailed analysis of a large sample of children with autism indicated that reports of somnolence usually ceased within 2 weeks of the last dose titration of risperidone (Aman et al., 2005). Most of the participants in the current trial had either a disruptive behavior disorder or autism, and it is reasonable, therefore, to hypothesize that risperidone may have reduced behaviors incompatible with learning performance, such as stereotypy or hyperactivity.

There is minimal literature on the effects of atypical antipsychotics on cognition in children and adolescents, forcing us to inspect the literature from adult trials (specifically in patients with schizophrenia). Purdon (1999) did an early analysis of the literature with atypical antipsychotics and reported enhancement of verbal fluency and learning, visuomotor tracking, and visual and verbal attention. Stip et al. (2005) analyzed 26 studies involving classical and atypical antipsychotic effects on cognitive-motor functioning in schizophrenic adults. (a) Motor performance findings: For risperidone, they noted one positive and two negative trials. In the case of other atypical antipsychotics (clozapine, olanzapine, quetiapine), they noted four instances of improvement and four cases of no change on tests of motor performance. (b) Attentional findings: Stip et al. (2005) located four risperidone trials showing significant improvement in attention and three trials that showed no change. For clozapine, they reported three trials of improved attentional performance, two showing no change, and reduced performance was noted in one other investigation. One trial of quetiapine showed significant improvement in attention during the acute trial, but at follow-up there was no change. (c) Memory findings: Stip et al. reported one trial showing improvement and another showing no change with risperidone; one trial with clozapine showed improved performance while four others showed no changes on memory tasks. Keefe et al. (1999) conducted a rigorous review of atypical antipsychotic drug effects in patients with schizophrenia, totaling 15 studies. Among the investigations that were properly controlled, Keefe et al. reported improvements in attention, in executive function, and in visuospatial analysis. Both Purdon (1999) and Keefe et al. (1999) lamented the lack of placebo controls, the lack of blindness, uncertainty about medication status at baseline, and occasionally the lack of any baseline measures on the outcome variables.

We were able to locate only three reports of the effects of risperidone (or any atypical antipsychotic) in children. Troost et al. (2006) assessed 24 children with pervasive developmental disorders and disruptive behavior who were clinical responders to risperidone in an open-label trial. All participants were randomized to a discontinuation study in which they received either risperidone maintenance or placebo substitution. On a divided attention task (which involved serial search in working memory), children assigned to placebo showed significant deterioration in performance, whereas those maintained on risperidone continued to improve. On a second task of "focused attention", (requiring the classification of stimuli by their position) there were no drug-related changes. Günther, Herpertz-Daahl, Jolles, and Konrad assessed the effects of risperidone in 23 children with ADHD on tests of sustained attention, divided attention, and the Go/No-Go paradigm. Drug effects were assessed by comparing all changes to the performance of a control group comprising age-and-IQ-matched normal controls. No medication effects were detected on any of the cognitive variables. Pandina et al. (2007) assessed verbal memory and sustained attention in children with disruptive behavior disorders. In this acute 6-week trial, there were no performance differences between children receiving placebo and those receiving risperidone.

Hence, there are minimal studies that have collected cognitive data in children with which 
to compare our results. However, on balance it seems that our lack of effect on the Continuous Performance Task is consistent with the findings reported by Troost et al. (2006) and by Pandina et al. (2007). There is no literature on seat activity in the context of performing cognitive tasks, but the reductions seen here seem entirely consistent with clinical reports of reduced overactivity with risperidone treatment (e.g., Aman et al., 2002; Research Units on Pediatric Psychopharmacology Autism Network, 2002). On balance, the studies conducted with adults having schizophrenia showed very mixed results insofar as memory is concerned, whereas we were unable to demonstrate enhancement or worsening of memory performance. Finally, this trial showed a significant reduction in static tremor, and this is consistent with several adult trials that reported improvements in fine motor function and visuomotor tracking.

\subsection{Behavioral effects}

Risperidone treatment was associated with improvement on the Conduct Problem, Hyperactivity, and Overly Sensitive subscales of the NCBRF and the Hyperactivity/Noncompliance subscale of the ABC. Aman et al. (2002) also saw reductions on all of these subscales in children with disruptive behavior disorders, whereas Snyder et al. (2002) observed reductions in all except the Overly Sensitive subscale. In a sense, this is a form of internal validation, as the same behavioral changes (except for Overly Sensitive) were seen on the same subscales across all three studies.

\subsection{Physical measures}

We noted a significant difference in heart rate, with significantly higher pulse rate in the risperidone condition. Aman et al. (2005) conducted a thorough analysis of AEs and did not observe significant differences in heart rate activity for 101 subjects with autism in the initial RUPP risperidone study. However, the assessment of heart rate in the current investigation was highly standardized; these participants were more cooperative than the participants in the RUPP autism study, and the conditions of assessment (following a mandatory 4-min of rest while sitting) were quite rigorous. This leads us to believe that this is a robust finding. Heart rate increases have often been reported with risperidone and other atypical antipsychotics (Tandon, 2002; Stigler, Potenza, \& McDougle (2001)). Consistent with the RUPP report and many other investigations (Aman et al., 2005; Martin et al., 2004), we observed significant increases in weight with risperidone.

\section{Limitations}

This modest study had a number of limitations. First, the sample was heterogeneous in that 11 participants had disruptive behavior disorders, 1 had ADHD, and 3 had high-functioning autism. Second, the sample size of 16 was small, although the crossover design helped to mitigate this. Third, we had little clinical control over the community sample used to augment our initial disruptive behavior disorder sample. Their medication work-up may have been different, the target symptoms likely were different, and their clinical response may have been larger or smaller than the participants whom we treated. Finally, our decision to discard the data from the participant whose medication expired was somewhat "arbitrary," although we believe that it was the correct decision. Conversely, the study had some unusual strengths as well. Foremost among these is the computer-controlled cognitive battery, which children generally enjoy and which has been shown to be drug sensitive in the past. Second, this study adds to a very small literature on the cognitive (and other) effects of risperidone in children. 


\section{References}

Aman, M. G. (1984). Drugs and learning in mentally retarded persons. In Burrows, G. D., \& Werry, J. S. Eds. Advances in human psychopharmacology. Vol. 3 (pp.121-163). Greenwich, CT: JAI Press.

Aman, M. G. (1991). Applications of computerized cognitive-motor measures to the assessment of psychoactive drugs. In W. E. Dodson, M. Kinsbourne, \& B. Hiltbrunner (Eds.), The assessment of cognitive function in epilepsy (pp. 69-96). New York: Demos Publications.

Aman, M. G., \& Singh, N. N. (1994). Aberrant behavior checklist-community. Supplementary manual. East Aurora, NY: Slosson Educational Publications.

Aman, M. G., Singh, N. N., Stewart, A. W., \& Field, C. J. (1985a). The Aberrant Behavior Checklist: A behavior rating scale for the assessment of treatment effects. American Journal of Mental Deficiency, 89, 485-491.

Aman, M. G., Singh, N. N., Stewart, A. W., \& Field, C. J. (1985b). Psychometric characteristics of the Aberrant Behavior Checklist. American Journal of Mental Deficiency, 89, 492-502.

Aman, M. G., Marks, R. E., Turbott, S. H., Wilsher, C. P., \& Merry, S. N. (1991). Methylphenidate and thioridazine in the treatment of intellectually subaverage children: Effects on cognitive-motor performance. Journal of the American Academy of Child and Adolescent Psychiatry, 30, 816-824.

Aman, M. G., Kern, R. A., McGhee, D. E., \& Arnold, L. E. (1993). Fenfluramine and methylphenidate in children with mental retardation and attention deficit hyperactivity disorder: Laboratory effects. Journal of Autism and Developmental Disorders, 23, 491-506.

Aman, M. G., Tasse, M. J., Rojahn, J., \& Hammer, D. (1995). The Nisonger CBRF: A child behavior rating form for children with developmental disabilities. Research in Developmental Disabilities, 17, 41-57.

Aman, M. G., DeSmedt, G., Derivan, A., Lyons, B., \& Findling, R. L. the Risperidone Disruptive Behavior Study Group. (2002). Double-blind placebo-controlled study of risperidone for the treatment of disruptive behavior in children iwth subaverage intelligence. American Journal of Psychiatry, 159, 1337-1346.

Aman, M. G., Arnold, L. E., McDougle, C. J., Vitiello, B., Scahill, L., Davies, M., et al. (2005). Acute and long-term safety and tolerability of risperidone in children with autism. Journal of Child and Adolescent Psychopharmacology, 15(6), 869-884.

Bilder, R. M., Goldman, R. S., Volavka, J., Czobor, P., Hoptman, M., Sheitman, B., et al. (2002). Neurocognitive effects of clozapine, olanzapine, risperidone, and haloperidol in patients with chronic schizophrenia or schizoaffective disorder. American Journal of Psychiatry, 159(6), 1018-1028.

Borison, R. L. (1996). The role of cognition in the risk-benefit and safety analysis of antipsychotic medication. Acta Psychiatrica Scandinavica (Supplement), 389, 5-11.

Botteron, K., \& Geller, B. (1998). Disorders, symptoms, and their pharmacotherapy. In J. S. Werry \& M. G. Aman (Eds.), Practitioner's guide to psychoactive drugs for children and adolescents (pp. 183-209). New York: Plenum.

Cuesta, M. J., Paealta, V., \& Zarzuela, A. (2001). Effects of olanzapine and other antipsychocitcs on cognitive function in chronic schizophrenia: A longitudinal study. Schizophrenia Research, 48, 17-28.

Ernst, M., Malone, R. P., Rowan, A. B., George, R., Gonzalez, N. M., \& Silva, R. R. (1999). Antipsychotics (neuroleptics). In J. S. Werry \& M. G. Aman (Eds.), Practitioner's guide to psychoactive drugs for children and adolescents (pp. 297-327). New York: Plenum.

Findling, R. L., Aman, M. G., DeSmedt, G., Derivan, A., \& Lyons, B. the Risperidone Disruptive Behavior Study Group. (2004). A long-term open-label study of risperidone in children with severe disruptive behaviors and subaverage IQ. American Journal of Psychiatry, 161, 677-684.

Gallhofer, B., Bauer, U., Lis, S., Krieger, S., \& Gruppe, H. (1996). Cognitive dysfunction in schizophrenia: Comparison of treatment with atypical antipsychotic agents and conventional neuroleptic drugs. European Neuropsychopharmacology, 6(Suppl.), S13-S20.

Geddes, J., Freemantle, N., Harrison, P., \& Bebbington, P. (2000). Atypical antipsychotics in the treatment of schizophrenia: Systematic overview and meta-regression analysis. British Medical Journal, 321, 1371-1376.

Green, M. F., Marshall, B. D., Wirshing, W. C., Ames, D., Marder, S. R., McGurk, S., et al. (2000). Does risperidone improve verbal working memory in treatment-resistant schizophrenia? American Journal of Psychiatry, 154, 700804.

Gunther, T., Herpertz-Dahlman, B., Jolles, J., \& Konrad, K. (2006). The influence of risperidone on attentional functions in children and adolescents with attention-deficit/hyperactivity disorder and comorbid disruptive behavior disorder. Journal of Child and Adolescent Psychopharmacology, 16, 725-735.

Honey, G. D., Bullmore, E. T., Soni, W., Varatheesan, M., Williams, S. C. R., \& Sharma, T. (1999). Differences in 
frontal cortical activation by a working memory task after substitution of risperidone for typical antipsychotic drugs in patients with schizophrenia. Proceedings of the National Academy of Sciences, 96, 13432-13437.

Kaufman, A. S., \& Kaufman, N. L. (1990). Kaufman Brief Intelligence Test (K-BIT), manual and easel. Circle Pines, MN: American Guidance Service.

Keefe, R. S. E., Silva, S. G., Perkins, D. O., \& Lieberman, J. A. (1999). The effects of atypical antipsychotic drugs on neurocognitive impairment in schizophrenia: A review and meta-analysis. Schizophrenia Bulletin, 25, 201-222.

Kløve, H. (1963). Clinical neuropsychology. In Forster, F. M. (Ed.). The medical clinics of North America. Vol. 47 (pp.1647-1658). New

York: Saunders.

MacQueen, G., \& Young, T. (2003). Cognitive effects of atypical antipsychotics: Focus on bipolar spectrum disorders. Bipolar Disorders, 56, 53-61.

Martin, A. et al. (2004). Weight and leptin changes among risperidone-treated youths with autism: Six-month prospective data. American Journal of Psychiatry, 161, 1125-1127.

Meltzer, H. Y. (1995). Role of serotonin in the action of atypical antipsychotic drugs. Clinical Neuroscience, 3, 64-75.

Mori, K., Nagao, M., Yamashita, H., Morinobu, S., \& Yamawaki, S. (2004). Effect of switching antipsychotics on memory in patients with chronic schizophrenia. Progress in Neuro-Psychopharmacology \& Biological Psychiatry, $28,659-665$.

NIMH (1985). AIMS (Abnormal Involuntary Movement Scale). Psychopharmacology Bulletin, (Special feature on Rating Scales and Assessment Involvements for Use in Pediatric Psychopharmacology Research), 21, 1077-1080.

Pandina, G. J., Bilder, R., Harvey, P. D., Keefe, R. S. E., Aman, M. G., \& Gharabawi, G. (2007). Risperidone and cognitive function in children with disruptive behavior disorders. Biological Psychiatry, 62, 226-234.

Purdon, S. E. (1999). Cognitive improvement in schizophrenia with novel antipsychotic medications. Schizophrenia Research, 35, S51-S60.

Purdon, S. E., Jones, B. D., Stip, E., Labelle, A., Addington, D., David, S., et al. (2000). Neuropscychological change in early phase schizophrenia during 12 months of treatment with olanzapine, risperidone, or haloperidol. Archives of General Psychiatry, 57, 249-258.

Research Units on Pediatric Psychopharmacology Autism Network (2002). A double-blind, placebo-controlled trial of risperidone in children with autistic disorder. The New England Journal of Medicine, 347, 314-321.3.

Snyder, R., Turgay, A., Aman, M. G., Binder, C., Fisman, S., Carroll, A., et al. (2002). Effects of risperidone on conduct and disruptive behavior disorders $\mathrm{n}$ children with subaverage IQs. Journal of the American Academy of Child and Adolescent Psychiatry, 41, 1026-1036.

Sprague, R. L., \& Sleator, E. K. (1977). Methylphenidate in hyperkinetic children: Differences in dose effects on learning and social behavior. Science, 198, 1274-1276.

Sprague, R. L., \& Toppe, L. K. (1966). Relationship between activity level and delay of reinforcement. Journal of Experimental Psychology, 3, 390-397.

Stigler, K. A., Potenza, M. N., \& McDougle, C. J. (2001). Tolerability of atypical antipsychotics in children and adolescents. Paediatrica Drugs, 3, 927-942.

Stip, E., Chouinard, S., \& Boulay, L. J. (2005). On the trail of a cognitive enhancer for the treatment of schizophrenia. Progress in Neuro-Psychopharmacology and Biological Psychiatry, 29, 219-232.

Tandon, R. (2002). Safety and tolerability: How do newer generation "atypical" antipsychotics compare? Psychiatric Quarterly, 73, 297-311.

Thorndike, R. L., Hagen, E., \& Sattler, J. (1986a). Guide for administering and scoring the fourth edition Stanford-Binet intelligence scale. Chicago: Riverside.

Toren, P., Ratner, S., Laor, N., \& Weizman, A. (2004). Benefit-risk assessment of atypical antipsychotics in the treatment of schizophrenia and comorbid disorders in children and adolescents. Drug Safety, 27(14), 1135-1136.

Troost, P. W., Althaus, M., Lahius, B. E., Buitelaar, J. K., Minderaa, R. B., \& Hoekstra, P. J. (2006).

Neuropsychological effects of risperidone in children with pervasive developmental disorders: A blinded discontinuation study. Journal of Child and Adolescent Psychopharmacology, 16, 61-573.

Wechsler, D. (1991). Manual for the Wechsler Intelligence Scale for children (3rd ed.). San Antonio, TX: The

Psychological Corporation. 